\title{
Lilly-Molecular Psychiatry Award: 2003 winners and 2004 call for submissions
}

\author{
Molecular Psychiatry (2003) 8, 567. doi:10.1038/sj. \\ mp.4001390
}

Molecular Psychiatry and Lilly have joined forces to develop a new award in our field. The LillyMolecular Psychiatry Award is given annually to the best original research submitted by a young investigator. Submissions are judged by a highly qualified group of academic leaders. ${ }^{\mathrm{a}}$ We are very grateful to the reviewers who considered many highly competitive submissions.

A universal agreement was seen on the choice of the winner for this competition, Dr Aaron R Jeffries, from the Institute of Psychiatry, King's College London, UK. Consensus was also reached to award an honorable mention to Dr Cynthia S Weickert, National Institute of Mental Health Intramural Research Program, USA. That honorable mention article, 'Reduced brain-derived neurotrophic factor (BDNF) in prefrontal cortex of patients with schizophrenia' is being published in this issue (pp 592-610). Aaron Jeffries's Lilly-Molecular Psychiatry Award article ' $\beta$-1,3-glucuronyltransferase-1 gene implicated as a candidate for a schizophrenia-like psychosis through molecular analysis of a balanced translocation' will be published in our next issue.

The Lilly-Molecular Psychiatry award and honorable mention were granted to research in schizophrenia, using respectively molecular genetics, and molecular pathological approaches. This is a reflection on the enormous advances that are being achieved in schizophrenia research. Such progress is also documented in our journal, with an increasing number of accepted articles being focused on schizohrenia. Dr Jeffries's article (co-authored by AJ Mungall, E Dawson, K Halls, CF Langford, RM Murray, I Dunham, and JF Powell) reports the mapping and sequencing of both chromosome breakpoints of a balanced $\mathrm{t}(6 ; 11)(\mathrm{g} 14.2 ; \mathrm{q} 25)$ chromosome translocation that segregates with a schizophrenia like psychosis. ${ }^{1}$ The authors analyzed the regions and found a number of confirmed and predicted transcripts. The chromosome 6 breakpoint region was

\footnotetext{
a The reviewers for the 2003 award were Drs Wade Berrettini (University of Pennsylvania, USA), David Collier (Institute of Psychiatry, UK), Michael Gill (Trinity College, Ireland), Jackie Hunter (GSK, UK), Steven Hyman (Harvard University), Elliot Gershon (University of Chicago, USA), Karl-Peter Lesch (University of Würzburg, Germany), W Ian Lipkin (Columbia University, USA), Pierre Magistretti (University of Lausanne, Switzerland), and Eva Redei (Northwestern University, USA).
}

found to be gene poor, the closest transcript being at $625 \mathrm{~kb}$ telomeric to the breakpoint. The chromosome 11 breakpoint was found to be $299 \mathrm{~kb}$ centromeric to the breakpoint. The closest gene $\beta$-1,3-glucuronyltransferase-1 (B3GAT1) is 299 centromeric to the breakpoint. B3GAT1 is the key enzyme during biosynthesis of the carbohydrate epitope HNK-1, which is present in several cell adhesion molecules that have a role in neurodevelopment. Interestingly, mice with a B3GAT1 gene deletion have defects in hippocampal long-term and in spatial memory formation. Dr Aarons et al. propose that polymorphic or other variation of the $11 \mathrm{q}$ telomere may affect B3GAT1 activity and that this may be a candidate gene for schizophrenia.

Dr Weickert's paper, co-authored by TM Hyde, BK Lipska, MH Herman, DR Weinberger, and JE Kleinman (pp 592-610), shows that pathology is now yielding important data on the biology of schizophrenia. The authors used RNase protection assays and Western blotting to detect a significant reduction in BDNF mRNA and protein in the dorsolateral prefrontal cortex (DLPFC) of patients compared with schizophrenia. They showed that at the cellular level BDNF was normally expressed at varying intensities in pyramidal neurons layers II, III, V, and VI of DLPFC. In postmortem tissue from patients with schizophrenia, neuronal BDF expression was decreased in layers III, V, and VI. It is suggested that such a decrease in BDNF levels of gene and protein expression indicates that intrinsic cortical neurons, afferent neurons, and target neurons, may receive less trophic support in schizophrenia.

We are now calling for submissions to our next LillyMolecular Psychiatry Award, which is aimed at recognizing outstanding research conducted by young investigators in the field of molecular psychiatry. Submissions should be within the scope of the journal, and must be received by 1700 (PST) Tuesday, 18 November 2003. There is no geographical restriction to this award - authors can be from any country. A one-page cover letter should accompany the paper summarizing its relevance, and confirming submission to the award in a manner that meets our guidelines. We encourage brevity and focus on the presentation of exciting new research results. For detailed instructions please contact our editorial office using e-mail: molecularpsychiatry@mednet.ucla.edu.

$$
\begin{array}{r}
\text { J Licinio } \\
\text { UCLA Laboratory for Pharmacogenomics } \\
\text { E-mail: licinio@ucla.edu }
\end{array}
$$

\footnotetext{
1 T Holland, C Gosden. Psychiatry Res 1990; 32: 1-8.
} 